\title{
What can the EU Learn from the USA in the Field of Innovation?
}

\author{
Lindita Komani ${ }^{1}$, Vito Bobek ${ }^{2} \&$ Tatjana Horvat ${ }^{3}$ \\ ${ }^{1}$ Research and Business Development at Campus Party, Tirana, Albania \\ ${ }^{2}$ University of Applied Sciences FH Joanneum, Graz, Austria \\ ${ }^{3}$ Faculty of Management, University of Primorska, Koper, Slovenia \\ Correspondence: Vito Bobek. University of Applied Sciences FH Joanneum, Institute of International \\ Management, Eggenberger Allee 11, 8020 Graz, Austria. Tel: 43-316-5453-6829.
}

Received: February 27, 2021; Accepted: March 14, 2021; Published: March 15, 2021

\begin{abstract}
The rationale for more European Commission (EC) support for Open Innovation is there, as a whole-of-society approach seems to be the best to address the challenges arising mainly from competition at the global level. This paper supported this view and was built as a case study research paper based on the EU and USA case studies. In the first sections, a theoretical framework is built, which establishes a link between R\&D, innovation, and competitiveness, introduces culture and military as factors influencing innovation, and shows how open innovation has changed innovation. A discussion evolves regarding the current position of the EU and EU countries in terms of innovation and what the EC is undertaking to address the identified challenges. The core section is dedicated to the case study, elaborates benchmarks, gains learnings from a country successful in the field of (open) innovation such as the USA, and suggests what the EC could concretely implement in the case of the EU. The outlook section suggests a few possible areas for future research and policies.
\end{abstract}

Keywords: innovation, open innovation, USA, the EU, the European Commission, defense, culture

JEL: O36; L98.

\section{Introduction}

The case of a whole-of-society approach to innovation and an Open Innovation Union is more relevant than ever. The EU needs to adapt to the challenges arising from outside its borders and developments and expectations from within. The open global market has reshaped and transformed the world. Competitiveness among countries has increased in every field of economy, with innovation being one of the most critical factors and indicators amidst them, which is increasingly seen in connection with a political, policy-making, and military perspective of the Cold War. The distinction between economy and politics is nowadays not so clear anymore. Western democracies are positioning and asking themselves: Are innovation and the entire development of the world going to be defined by democracies or by a rising authoritarian force such as China? The $5 \mathrm{G}$ debate and the supply issues arising with the COVID-19 pandemic have intensified throughout this year, and the accusations around economic espionage and forced tech transfers. Which direction is the world heading to, and what will be the position of the EU?

While trade has been the main focus in the internal European market over the years, innovation has been recognized now as a primary focus, too, as also shown in the priorities for the 2021-2027 EU budget. However, what is the best method to foster and develop innovation? What can the EC (EC) do that countries on their own cannot? Can the EC enable a natural innovation movement within the EU borders, and how willing would the innovation ecosystem stakeholders, including academia, business, and citizens be, to participate in such a coordinated effort?

Open innovation is more than a mere trendy phrase. Some call it a concept, while some refer to it as a paradigm. Coined in 2003, over the years, Open Innovation has become a widely used method in the private and government sector worldwide. Dozens of research papers have been written on it, but it has not yet been theorized. Is Open Innovation a universal remedy for what is missing in the innovation realm?

As confirmed by international innovation rankings, such as the Global Innovation Index, EU countries are very well positioned in innovation, but different EU countries show quite a different level of development in this respect. Some might lack the attention on the topic as they have more urgent challenges to address, some might lack the infrastructure, but all would undoubtedly need more funding and a more supportive hand able to identify everyday 
needs, to find how to address them, and to coordinate the work to create a common path. The EC could and should have such a role.

With the willingness demonstrated and with the innovation dedicated funding of over $€ 80$ billion for Horizon Europe, and also through other financing structures, the question is: what can the EC do better than what it has been doing until now to better support innovation? Moreover, how can it make the best use of the policy goal set as a basis of work since 2015, namely Open Innovation?

Benchmarks with countries that are successfully implementing the Open Innovation method and leading positions worldwide in terms of innovation are the best method to come to new learnings that might help address the issues and questions raised in this introductory note. Furthermore, there is much to learn, as well as there is much to think about what might be some somewhat neglected factors that influence innovation and how they can best be addressed to achieve better results.

A strong motivation for this paper is the vision that the EU can be a top destination for talents from all over the world, where innovation is generated, disseminated, and absorbed. With this vision, the following set of goals and related research questions stand at its core: (1) to show how open innovation has changed the approach to innovation; (2) to introduce factors such as culture and military, which influence innovation; (3) to discuss the current position of the EU and EU countries in terms of innovation and what the EC is undertaking to address the current challenges; (4) to elaborate benchmarks and gain learnings from country successful in the field of (open) innovation such as the USA.

This is a case study research paper that examines the phenomenon and the process of (open) innovation. Even though the focus is on this single subject, the paper will be designed as a comparative investigation that shows a relation of innovation to economic growth, innovation to culture, innovation to the military. (Note 1)

In this paper, the theoretical approach is based on Francis Fukuyama, Raquel Fernandez, Lawrence Harrison, and Samuel Huntington. They showed how cultural factors such as trust, group orientation, and risk-taking influence innovation and growth. While arguing about the importance of cultural factors in the US innovation, Atkinson (2014, pp.8-10) emphasizes the nature of customer demand relying on Michael Porter's work on competitive advantage, risk-taking and entrepreneurship, attitudes toward science and technology, collaborative culture, time horizon and willingness to invest in the future, as crucial cultural elements. Additionally, the paper also builds on the study conducted by Bond (1987), resulting in the identification of a dimension which the author labeled as Confucian Work Dynamism, and, upon permission, Hofstede (2011, p.13) was able to introduce in his dimensions as Long-versus Short-Term Orientation. In the 2000s, using data from the World Values Survey, Minkov enabled the extension of the list of dimensions up to six (Hofstede 2011, pp.7-8). All these approaches were combined in this paper.

How military and civil sector innovations have influenced each other is made clear in the works of Avadikyan et al. (2005, p.161). As referred by Schmid (2017, p.3), Mowery proposes several channels as tools connecting expenditures in the military area and innovation in the civil sector. In the most thorough review organized by using a free way to prepare a cowritten work by 23 researchers on Open Innovation, Bogers et al. (2016) also list some of the topics that researchers in this paper have addressed. The many case studies presented by different researchers, including Chesbrough (2020) and recent surveys from North America and Europe, show a long way ahead for Open Innovation. Moreover, among others in this way, public investments are necessary to sustain the success of Open Innovation over time and to be able to drive process improvements in all businesses (Chesbrough 2020, p.16). Furthermore, designing and managing innovation communities will be increasingly crucial in Open Innovation's future (Chesbrough 2020, p.47). The authors of this paper address all these issues.

The case study to be presented here aims to enable an in-depth analysis, interpretation, and discussion, which results in specific recommendations to be made to the EC to act and improve the situation concerning (open) innovation in the EU.

\section{Research Questions and Methodology}

This paper represents a case study research that examines the phenomenon and the process of (open) innovation. Although the focus is on this single subject, the paper was designed as a comparative investigation that shows a relation of innovation to economic growth and the impact of culture and military sector on innovation.

The methodology used comprises literature review, comparisons based on innovation rankings, scores related to cultural dimensions and data related to military, case study analysis, and benchmarking. Which methods were applied for particular research questions are described below. 
The specific research questions are related to the specific goals presented above. Also, the methodology to be used for addressing these questions is presented here:

- Research Question (RQ) 1: How open innovation has changed the approach to innovation? The addressing of this research question will be purely theoretical, based on a literature review.

- RQ 2: What is the influence of culture and military on innovation? The addressing of this research question will be purely theoretical, based on a literature review.

- RQ 3: How is the EU positioned in terms of innovation (from an internal and external perspective)? This research question will be theoretical and empirical, with some comparisons based on innovation rankings, scores related to cultural dimensions, and military data.

- RQ 4: What can the EU learn from the best Open Innovation cases worldwide (US)? The addressing of this question will be based on case study analysis and benchmarking.

The selection of the case study included considering the following questions (Note 2):

- Does the case represent unusual or atypical examples of (open) innovation that require more in-depth analysis?

- Does the case provide important insights or cast light upon a previously hidden issue regarding (open) innovation?

- Does the case challenge and offer counter-points to prevailing assumptions on (open) innovation?

- Does the case provide an opportunity to perform action leading to resolving the challenges to (open) innovation in the EU?

- Does the case offer new directions in (open) innovation research?

Section 3.1 provides the fundamental theoretical framework for the paper. Research conducted on this topic has focused on different countries and regions, and this is also reflected in the presentation of literature review, which is organized as follows: first, the focus is given to research dedicated to EU countries, with a regions' perspective and then a nations' perspective, followed by research on OECD countries, and then the USA. This section addresses a part of RQ 1.

Section 3.2 focuses on two factors that influence innovation. The first part is dedicated to the contribution of culture to innovation, while the second one contributes the military to innovation. This section addresses RQ 2.

Section 3.3 complements the theoretical framework by reviewing several research results of interest related to Open Innovation. Focus is placed on the coining of the definition of Open Innovation, criticism on the original concept and its revision, the way toward a multilevel analysis of Open Innovation, and finally, the limits and failures of Open Innovation. This section addresses a part of RQ 1.

Based on the previous section's theoretical framework, the empirical analysis starts in section 4.1 with the EU and the position where it stands in terms of innovation. A perspective from the outside will be given by presenting where EU countries stand in the Global Innovation Index. The Transformation Map developed by the World Economic Forum will also provide a framework based on which the existing and upcoming challenges for the EU can be judged. This section addresses a part of RQ 3.

Section 4.2 partly addresses RQ 3 and focuses on the change in approach that has recently occurred, followed by a presentation of the considerable rise in the amount of funding for the 2021-2027 period, the new structure of the European Innovation Council, and more straightforward rules to be implemented in managing funds and to conclude, the situation surrounding the Open Innovation topic and how the EC is handling it. This chapter addresses part of RQ 3.

The case study to be tackled and high value in the times we live is that of the USA. Section 4.3 starts with the specific case of the USA. It tackles some of the internal developments in the USA related to innovation, it gives a focus on the efforts undertaken regarding Open Innovation, and then it provides benchmarks. This section serves as a basis for addressing RQ 4 and addresses it.

Section 4.4 addresses RQ $3 \& 4$ and is built on two pillars. The first one focuses on the benchmarks among EU countries and the EU countries' benchmarks with the USA and partly addresses RQ 3. The frameworks used are those of the GII index, the military service data collected from CIA Factbook, and then the Hofstede Cultural Dimensions scores for the respective countries. The second one focuses on the learnings that can be gained from the USA and includes a discussion about what the EC can do about the good examples coming from the USA and addresses RQ 4. 
Section 5 discusses the main findings, while Section 6 summarizes and gives an outlook related to potential developments and suggestions for future research and policies.

\section{Literature Review}

\subsection{Culture and Military as Factors Influencing Innovation}

Research conducted for this paper showed that culture and military are also essential factors to consider when dealing with innovation. As both these factors will appear in the empirical part when dealing with the USA, it is crucial to give a theoretical framework about culture and military.

\section{Contribution of Culture}

As Atkinson notes, researchers including Francis Fukuyama, Raquel Fernandez, Lawrence Harrison, and Samuel Huntington showed how cultural factors such as trust, group orientation, and risk-taking influence innovation and growth. While arguing about the importance of cultural factors in the US innovation, Atkinson emphasizes the nature of customer demand relying on Michael Porter's work on competitive advantage, risk-taking and entrepreneurship, attitudes toward science and technology, collaborative culture, time horizon, and willingness to invest in the future, as crucial cultural elements (Atkinson 2014, pp.8-10).

Atkinson's works are worth being quoted and presented in more detail, but as they do not provide quantitative results that can be used to compare countries with each other, a specific theory was opted in the theoretical framework to be used in this paper.

Hofstede's framework of the cultural dimensions is a tool at disposal to understand and describe the effects of national culture on individuals' behavior. Developed by Gert Hofstede, it has its origins in the extensive study of international business life and wide usage within the business world. It dominates in cross-cultural psychology and international management (Beugelsdijk \& Wenzel 2018, p.1469).

Ever since there have been many replications of analyses confirming the results of Hofstede's work, the study conducted by Bond in 1987 resulted in the identification of a dimension which the author labeled as Confucian Work Dynamism, and, upon permission, Hofstede was able to introduce in his dimensions as Long-versus ShortTerm Orientation (Hofstede 2011, p.13). In the 2000s, using data from the World Values Survey, Minkov enabled the extension of the list of dimensions up to six (Hofstede 2011, pp.7-8).

\section{Contribution of Military}

Military innovations have had a long history of influence and diffusion on the civil sector innovations, which are primarily debated in the scientific literature due to their more open nature. Nevertheless, many defense innovation research papers from which a basis for literature review may be drawn.

How military and civil sector innovations have influenced each other is made clear when distinguishing among two critical periods in time (Avadikyan et al. 2005, p.161):

- The first period developed between World War II and the mid-1980s. The Cold War led to high Military expenditure, which created significant technological spin-offs in the civil sector. The military and industrial perspectives were combined in this period as provided by examples from this period which stem from R\&D funded by the military, including semiconductors, telecommunication satellites, civil launchers, aircraft, composite materials, and other technologies.

- The second period started from the mid-1980s and is characterized by a decrease in military expenditure. Innovation efforts in the civil sector and the technological flow experienced a significant shift, now from the civil to the military.

While there is strong support for national defense R\&D processes, little research has been conducted on how defense funding and technologies impact innovation systems, with the secrecy related to defense technology being one main reason for this development. The existing empirical research to understand how military technology is diffused is based on a case study approach (Schmid 2017, p.2).

As referred by Schmid (2017), Mowery proposes the following channels as tools connecting expenditures in the military area and innovation in the civil sector (Schmid 2017, p.3):

1. Military R\&D may be connected to institutions or researchers engaged in activities that increase innovation in the civil sector. The establishment of a university-based US research infrastructure that has led to many civil sector innovations is partly due to this kind of military expenditure.

2. Defense spending can lead to more civilian innovation due to increased demand for new technologies through government procurement. 
3. Defense R\&D expenditure can produce knowledge and technologies which set a basis for further subsequent innovations (as it was, among others, the case of the internet, the semiconductors, and more).

Schmid's study uses a sample of 2112 military patents and employs technological diffusion as a dependent variable. The most striking finding of this study is that military and civilian patents diffuse at similar rates, and features of the defense innovation system do not limit their diffusion as it has been contended (Schmid 2017, p.12).

It is essential to emphasize at this point that this paper suggests looking beyond the innovation investments in the military and also consider another significant factor that is related to the human and educational part of the military, which would include: the training that is completed, talent discovery, hands-on jobs that might be undertaken while on duty, including learning about technology and how to use it, learning about the value of working in collaboration with others, learning about the value of trust, learning about the value of the country and the value of defense and defense innovation.

\subsection{Open Innovation}

Since the phrase was first coined by Chesbrough (2003), interest in Open Innovation as a practical approach to innovation and a research field has increased exponentially (West \& Bogers 2017, p.43). He differentiates in his initial work between Closed Innovation and Open Innovation Paradigm. As opposed to Closed Innovation, the Open Innovation paradigm allows for a very different approach to the innovation topic. Ideas are free to come from the inside and outside. The same is true about how they move further to the market (Chesbrough 2003, p.43). The deliberate opening of the organizational boundaries for the innovation process defines Open Innovation (Julius Raab Stiftung 2015, p.16).

The abundance of knowledge in every field is today facilitated by low-cost internet and high transmission rates. The new logic introduced with Open Innovation exploits the diffusion of knowledge. Good research practice is not based exclusively on inventing knowledge, but it also includes accessing and integrating external knowledge. A company can benefit from the rivals' use of the intellectual property they have produced, which should be considered while managing IPR. Even investment in young startups might be worth exploring as an area of potential future interest (Chesbrough 2003, pp.51-52).

However, increasingly, Open Innovation is linked to various innovation phenomena, and the studies that have been conducted bring insight and perspectives on different innovation processes, but what they lack is a connection to each other (Bogers et al., 2016).

In the most thorough review, which was organized by using a free way to prepare a cowritten work by 23 researchers on Open Innovation, Bogers et al. (2016) list also some of the topics that researchers have addressed over the years:

- Users as innovators;

- Innovation communities;

- Open-source software development;

- Knowledge sourcing;

- Crowdsourcing and distributed problem solving;

- Inter-organizational alliances;

- Licensing agreements;

- Collaborations with and within communities, crowds, or networks, including users, citizens, scientists, etc.

They argue that more multilevel analysis is necessary for the phenomenon of Open Innovation, which has not yet been theorized as it has the potential to be so. In this regard, they suggest intra-organizational, organizational, inter-organizational, extra-organizational, industrial, regional, and societal levels of analysis. While addressing this complexity, they propose a framework for future Open Innovation research that highlights Open Innovation behavior and cognition, Open Innovation strategy and design, Open Innovation stakeholders, Open Innovation ecosystem, and open governance as research categories that cut across different levels of analysis which may help in creating connections between the various levels.

Further interesting development between research and practice is the Open Innovation 2.0 paradigm referred to as an "invention." It is promoted as such by the Open Innovation Strategy and Policy Group (OISPG), an industryled informal group of experts who have published many reports to inform the interested audience about the open innovation cases in the EU and elsewhere. 
The many case studies presented by different researchers, including also Chesbrough (2020), as well as recent surveys from North America and Europe which confirm that $78 \%$ of the companies use at least some elements of Open Innovation (Chesbrough 2020, p.28), show that there is a long way ahead for Open Innovation. Moreover, among others in this way, public investments are necessary to sustain the success of Open Innovation over time and to be able to drive process improvements in all businesses (Chesbrough 2020, p.16). Furthermore, designing and managing innovation communities will be increasingly crucial in Open Innovation's future (Chesbrough 2020, p.47).

\section{Empirical Analysis}

\subsection{How is the EU Positioned in Terms of Innovation?}

\section{Measuring Innovation Achievements in the EU through the Horizon Dashboard}

Horizon Dashboard is a software developed by EC to provide consolidated public data about IPR applications and scientific publications produced as part of the projects funded by the EU Research Framework Programmes FP7 and Horizon 2020 (EC 2019a, p.1).

Under the Intellectual Property Rights section, information is provided for patents, trademarks, registered designs, utility models related to the project's outputs, from the beginning until after the project's termination (EC 2019a, p.1). Under the Scientific Publications section, information is shared about articles (non-peer-reviewed), peerreviewed articles, conference proceedings, book chapters, monographic books, paper dissertations, and others.

\section{The European Innovation Scoreboard}

European Innovation Scoreboard 2020, which provides a comparative assessment of the research and innovation performance in EU countries, other European countries, and regional neighbors, shows that there has been a rise of 8.9 percentage points between 2012 and 2019 in the overall performance of the EU. The scoreboard places the countries in 4 categories: Innovation Leaders, Strong Innovators, Moderate Innovators, and Modest Innovators. The European Innovation Scoreboard is calculated based on 27 indicators compared to 80 of the Global Innovation Index.

\section{Comparing the EU to the world: Global Innovation Index}

Twenty-seven of the 50 top-ranked countries in the Global Innovation Index (GII) 2019, which comprises 129 countries, are EU countries. The table below shows how the rankings are distributed.

Table 1. Ranking of EU countries in Global Innovation Index 2019 (Note 3)

\begin{tabular}{lllll}
\hline Rank 1-10 & Rank 11-20 & Rank 21-30 & Rank 31-40 & Rank 41-50 \\
\hline (2) Sweden & (12) Ireland & (21) Austria & (31) Slovenia & (41) Greece \\
(4) the Netherlands & (16) France & (23) Belgium & (32) Portugal & (44) Croatia \\
(6) Finland & (18) Luxem. & (24) Estonia & (33) Hungary & (50) Romania \\
(7) Denmark & & (26) Czech Rep. & (34) Latvia & \\
(9) Germany & & (27) Malta & (37) Slovakia & \\
& & (28) Cyprus & (38) Lithuania & \\
& & (29) Spain & (39) Poland & \\
& & (30) Italy & (40) Bulgaria & \\
\hline
\end{tabular}

Source: Global Innovation Index 2019, p.xxxiv

An analysis of the GII rankings in 2007 - 2019, focused on ranks 1-10, shows that only 7 EU member countries have managed to be part of it. The Netherlands leads by having been 12 times in the top 10 list, followed by Sweden that has been on this list 11 times, and then Denmark and Finland 10 times. Sweden is the best-ranked country among the EU members throughout these editions. It has held second place in 7 editions. No EU country has reached the $1^{\text {st }}$ rank, with Switzerland being its holder since 2011.

GII still identifies a few concerns that might be considered as challenges for the EU. First, the differences in innovation performance within the EU region are persistent. Secondly, while referring to previous literature addressing the "EU paradox" since the mid-1990s, GII shows that the EU has higher performance in academic components such as scientific publications and lower performance on firm innovation components such as R\&D or innovation outputs. The same may also be identified by analyzing the Horizon Dashboard presented in figures 3 and 4. Thirdly, GII also shows that entrepreneurial activities in the EU lag behind those in the US, still it 
recognizes that the startup scene in the EU has experienced new positive developments (Global Innovation Index 2018, p.46).

\section{World Economic Forum}

World Economic Forum (WEF) gives insight into their research findings dealing with the EU's transformation influenced by the following factors: Great Power Politics, Transatlantic Relations, Consequences of the Euro crisis, the Digital Age, Shifting Trade Environment, as well as Refugees and Migration. These factors are composed of many subfactors, which contribute to them becoming of significant importance for recent and upcoming developments. Directly or indirectly, these developments will lead the EU to decide how to adapt in the near and longer-term future, address the challenges better, and what kind of budget to allocate to each of them.

By comparing developments worldwide and identifying strengths, weaknesses, opportunities, and threats, the WEF and McKinsey count several challenges that Europe needs to overcome in the future such as (WEF \& McKinsey 2019, p.4):

- Private investment in R\&D as of 2015 was $\$ 90$ billion lower than that in the US;

- $\quad 90 \%$ of the R\&D investment is concentrated in only 8 EU countries;

- Tech and entrepreneurial talent is lacking in Europe, and by 2020 it is expected that around 760000 ICT job positions will be unfilled.

They call upon Europe to set a new ambition for itself: to compete for global innovation leadership. They consider that there is a need for Europe to establish an innovation model built on the following ten blocks:

1. Pan-European approach, which is needed to help create a spirit of Innovation Union and to create synergies and better coordination;

2. Corporate-start-up collaboration, which would fall under the concept of Open Innovation;

3. Innovation funding;

4. Enabled government and public institutions;

5. Data access and protection, which would facilitate Open Innovation;

6. Entrepreneurial talent;

7. Digital education, reskilling, and upskilling;

8. Gender diversity;

9. Digital infrastructure and interoperability;

10. Harmonized legislation and standards.

The scale needed to compete globally could be achieved, among others, via:

- Funding for breakthrough innovation, creating "cross-sector innovation strategies and platforms for high potential industries, including regulatory sandboxes for experimentation;

- Changing data dynamics by opening government-owned non-personal and anonymized data for research;

- Boosting talent by reversing migration flows and attracting entrepreneurial talent; leveraging new technologies to re- and upskill workers; increasing the level of talent diversity, including female STEM talent, and attracting women to become tech entrepreneurs.

- Creating demand at scale by leveraging public sector leadership to leverage public procurement rules; implementing a digital-by-default principle for public services; driving convergence on a standard.

\subsection{How is the EC Reacting to the Challenges and the Increased need for Innovation?}

\section{A Change in Approach}

A new mission-oriented approach, which could prove critical for European competitiveness as it can help steer more innovative investments towards tackling societal challenges in a more focused and problem-solving manner, is already in place within the Horizon 2020 framework. Missions have been identified to be potentially able to provide the means to focus research, innovation, and investments on solving critical problems and where the added value to the EU is the greatest (Mazzucato 2018, p. 6, 10). Missions can support fostering experimentation to achieve the mission objective (Mazzucato 2018, p.12). They can also stimulate new forms of collaboration between fundamental research (which will continue to be funded by the European Research Council) and applied research 
(Mazzucato 2018, p.12). In the new MFF proposal, the EC embraced the mission-oriented approach, which, based on today's challenges, can offer a new way to align EU funds' efforts in innovative solutions.

Furthermore, the funds will be focused on excellent players to improve their global competitiveness and foster economic growth. The excellent Horizon Europe applicants, who will not obtain funds due to intense competition, will be accorded "seals of excellence," which they can then use when applying for alternative funds, in most cases, structural funds. This approach would also facilitate higher flexibility between budget lines and help steer regional funds towards innovation (Beun et al., 2019, p.10).

\section{A Considerable Rise in the Amount of Funding}

In July 2020, the European Council decided on the 2021-2027 Multiannual Financial Framework (MFF) as well as on the Next Generation EU facility, which was suggested to support a recovery effort as a result of the COVID19 pandemic and the effects it has on the EU economy and society (European Council 2020, p.1).

The MFF in this upcoming period, with an overall amount for commitments of EUR 1074.3 billion, is structured in 7 different headings out of which three are wholly or partly dedicated to research, innovation, and innovative solutions, namely (European Council 2020, p.10, 17, 21, 53):

- Heading 1 - Single Market, Innovation and Digital: EUR 132,781 million of commitment

- Heading 2 - Cohesion, Resilience, and Values: EUR 377,768 million of commitment

- Heading 5 - Security and Defence: EUR 13,185 million of commitment

It is clear that Horizon Europe did not get EUR 100 billion of commitment as it was announced in 2019, but almost $25 \%$ less than that. Despite that, funding for innovation also comes from other directions. Fascinating is that funding for defense has increased significantly, and as mentioned, it reflects changes that have occurred in the geopolitical situation. For the first time in the EU's history, defense and security are featured in a separate section in the MFF, and this also manifests the intention expressed by the new Commission to be a geopolitical Commission (Friedrich Naumann Foundation, 2020).

\section{European Innovation Council}

Regarding the new structures, as innovation has never occupied such an important role within the EU programs like it is happening in the past three years, a new structure was conceived to bring disruptive and breakthrough innovations from lab to market application and help startups and SMEs scale up their ideas. The European Innovation Council (EIC) was launched as a pilot in 2019 by the EC, following July 2018 by the European Council. A total amount of around $€ 3$ billion was provided in funding and networking opportunities, mentoring, and coaching, as well as receiving strategic advice to upgrade the innovation ecosystem in Europe. EIC will act as a complement to the European Institute of Innovation and Technology (EIT) (EC, 2019b) (EC, 2019c). EIC is foreseen to act as a one-stop-shop for innovators by providing support throughout the innovation process by its two instruments: EIC Pathfinder to support early applied research and EIC Accelerator commercialization scaleup phase (Executive Agency for SMEs, p.4-5).

According to their KPIs, each euro invested by EIC has led to follow-up private investment in the size of (Executive Agency for SMEs, p.10):

- $\quad$ x 3.3 - for companies that were selected in 2015 over four years, and

- $\quad$ x 2.9 - for companies that were selected in 2016 over three years.

Furthermore, scale-ups that are valued at over $€ 100$ million composed $5 \%$ of the portfolio. (Executive Agency for SMEs, p.10).

\section{EIC Accelerator}

The EIC Accelerator provides grants and blended finance, and companies are selected in a process that has a success rate of 2-3\% (Executive Agency for SMEs, p.14). An analysis made based on the data provided interestingly shows that Spain and Italy are the countries with the most significant number of companies present in the portfolio, 930 and 701 respectively, and only 16 of the $27 \mathrm{EU}$ member countries are present in the actual portfolio (Executive Agency for SMEs, p.18-19). This could suggest that Spain and Italy have more companies with innovative ideas or that their financial market is not as much developed as that of other countries that have fewer companies present because innovative companies might find the funding elsewhere. The top three sectors in the portfolio are health (1262 companies), energy (922 companies), and software enterprise (735 companies) (Executive Agency for Small and Medium-Sized Enterprises, p.22). Altogether EIC Accelerator portfolio 
companies were able to attract $€ 5.3$ billion of private follow-up funding, out of which $74 \%$ (or $€ 4$ billion) came from equity investments (Executive Agency for SMEs, p.26).

\section{EIC Pathfinder}

EIC Pathfinder, on its side, has a different way of working, as it focuses on the researchers working on innovative ideas all over Europe. FET Open, the first of its two lines of action, is operating as a bottom-up scheme to explore innovative technologies that might be game-changers in the future, while FET Proactive is seeking to create a critical mass of European researchers working on the exploration of topics that might be of value for the future (Executive Agency for SMEs, p.37). So far, 431 projects have been funded, which have included more than 2774 participants and have received total funding of $€ 1.2$ billion. The average project has 6.4 participants, and they are well-spread in all research sectors: $50 \%$ from academia, $25 \% \%$ from research organizations, and $22 \%$ from private companies. The percentage of projects involving SMEs under this scheme, namely $60-70 \%$, is much higher than under Horizon 2020 with a quota of $33 \%$. Another interesting fact is that the EIC participants come from 49 countries, including all EU member countries. Still, $5 \%$ of them come from only five EU member countries: France, Germany, Italy, Spain, and Netherlands (Executive Agency for SMEs, p.40). This again is a sign that the most critical researching capacities are concentrated in the EU area and what kind of gap exists with the rest of the EU countries.

\section{New Rules}

Regarding the simplification of rules, the Council adopted the Omnibus regulation in 2018 to revise the financial rules and make them simpler and more result-centered. The changes include: reimbursement of costs has been made easier; single checks and assessments; more straightforward rules for the combination of funding sources; single rulebook. These improvements are expected to lead to a substantial reduction of red tape for all those dealing with implementing the EU budget (EU Monitor, 2018) (European Council, 2018).

\section{Open Innovation in the EU and the EC}

$\mathrm{EC}$ has furthermore identified the roles of different actors in Open Innovation. For the public sector, a central role is seen concerning promoting Open Innovation. For the financial sector, building more innovation-friendly financial instruments is considered a suggestion for the future. Businesses are recognized to have a critical role in innovating, while academia plays a role as a knowledge producer, co-creator, and skilled human capital generator. Citizens are regarded to have a transversal role in bringing innovation to the market, as they create demand, can finance innovative projects of interest to them, can themselves be a source of innovative ideas, and can have a say in what research is meaningful to them (EC, 2016).

The right regulatory environment still needs to be created or rewritten to remove obstacles to innovation and encourage innovators and entrepreneurs to increase their efforts. More efforts also need to be undertaken to facilitate the rise of more private financial instruments to create similar innovators' opportunities to those in the US. The third pillar of action includes the reshaping of existing instruments and creating new institutions such as European Innovation Council (EC 2016, p.18).

Proposals to fund Open Innovation, through increasing the funds for VC investment and supporting the creation of university spin-offs to commercialize research discoveries and promote cooperation and competition and expand open government were made already in 2011 (Chesbrough et al. 2011, p.4).

\subsection{Case Study: The USA}

Coined as a definition at a theoretical level Chesbrough (2020), the USA may be considered the fatherland of Open Innovation. In terms of innovation, the USA is facing similar challenges to the EU countries, especially concerning China's rise and the methods that this country is using to acquire innovation made in the USA or made in EU countries. The USA is the country which, from a political and cultural perspective, is the closest one with the EU countries. Furthermore, both the USA and the EU are composed of many states, although the former is a federation, and the latter is not officially a federation or even a confederation. Like in the past, the USA's military still constitutes a vital ecosystem for high-level innovation development.

For years the bells have been tolling in the USA, and at last, they have been heard. A significant shift in policy is taking place about innovation which includes: (1) US\$100 billions of investment in the National Science Foundation, which is interpreted as a measure of symbolic value at a time when public investments in Research \& Development are needed most, and (2) a change in the direction about the relationship with China which is heavily based on the developments related to intellectual property theft and economic espionage. Prominent personalities, including the Secretary of the Department of State, the General Attorney, the FBI Director, and the National Security Advisor to the US President, have given public speeches to announce this shift. Experts are speaking 
about the start of a new Cold War with a strong focus on innovation. This critical development unexpectedly turned all attention toward a field neglected by the US government, as it has been considered that the private sector deals best with it and that America is still the home of innovation (Feulner, 2018).

\section{Internal Developments in the USA Related to Innovation}

The US nowadays is considered to have a reasonably good business and regulatory environment but a weak innovation policy environment, especially compared to nations such as Japan or a large part of Europe that have robust innovation policy systems. All these factors determine innovation, meaning that there is much room for improvement in the US national innovation system (Atkinson 2014, p.23).

The business environment consisting of the following broad factors: market, firm structure, and behavior, as well the system for financing business and related social and cultural factors, which will be covered in a separate subchapter in this paper, is considered to be in good shape. One of the most vital points of the American business environment is managerial talent, and perhaps the weakest point is related to the time horizon and risk appetite of firms. The obsession of investors with short-term results leads to management decisions that destroy long-term value, including the prospective investment in innovation (Atkinson 2014, p.2).

The trade, tax, and regulatory environment are also considered to be in good condition. The weakest points are related to the regulatory burdens on innovation that have grown in the past 15 years, both in terms of extent and orientation.

The innovation policy area is less sophisticated and developed, partly due to the dominance of the neo-classical economic consensus in the US, which regards policies of these kinds as an inappropriate intervention in the economy, and partly due to the "Hertz Syndrome" of which Americans think that they are number one and do not need to try harder. The most favorable characteristics of the USA's national innovation system are to be found in the systems of knowledge flows, the innovation clusters, and industry collaboration systems, including here Silicon Valley and North Carolina's Triangle Park, which have created essential references regarding the power of clusters. Furthermore, collaboration with academia and research institutes is favored by several factors. First of all, it is culturally-based since pragmatism is one main reason that leads universities to see collaboration with industry as essential to advance knowledge but also to have financial gains. In this regard, it is universities themselves that compete with each other to work with industry. Then, in American universities, a university lecturer and researcher can start collaborating with industry even before becoming a full professor. Finally, it is the government that supports this collaboration. The challenge comes in the commercialization part of the collaboration, which is less effective (Atkinson 2014, p.17).

The human capital system shows weaknesses in several areas. The US shows poor performance in the PISA. (Note 4) and TIMMS (Note 5) Research related to the achievement of pupils, which reflects structural problems in the K-12 education system. The main problems regarding higher education are related to the fact that it seems challenging to create a pipeline of US students choosing science, technology, education, and mathematics as their fields of study, while there is a large share of foreign-born students. According to research conducted by the National Foundation for American Policy, $81 \%$ of electrical engineering graduates, $79 \%$ of computer science graduates, and $75 \%$ of industrial engineering graduates were citizens of other countries (Watney, 2020). In the skills and technical training field, the responsibility seems to be falling on the private sector. A significant issue addressed by most of the critics of the US's innovation system is the low funding support for R\&D produced in universities and federal labs. Other indicators showing that there has been a decline in entrepreneurship are the share of firms younger than five years old, which declined from $47 \%$ in the late 1980 s to $39 \%$ in 2006 , as well as job-to-job mobility, within job mobility and geographical mobility, which have declined as well (Naudé, 2019). The reasons for this decline in entrepreneurship are not clear.

\section{Open Innovation in the USA}

Both the private and US governments are active users of the Open Innovation method to gain ideas and solutions for the problems and challenges arising in their activity.

A large-scale survey of companies conducted by Chesbrough and Brunswicker examined companies' Open Innovation practices in Europe and North America with a sample restricted to companies with annual sales above $\$ 250$ million and more than 1000 employees. They found out that $78 \%$ of the companies practiced at least some Open Innovation elements (Chesbrough 2020, p.69). They also investigated the firm's satisfaction, resulting in a slightly positive inclination toward Open Innovation (Chesbrough 2020, p.83). They also identified the exciting fact that despite the not so high-level perceptions, no firm had abandoned Open Innovation, something that, in 
their opinion, suggests that the firms are willing to learn more on how to make better use of Open Innovation to reach more satisfactory results (Chesbrough 2020, p.83).

Among the civil government institutions which have gained much experience with Open Innovation is also NASA. Through its many different initiatives run by the Center of Excellence for Collaborative Innovation, NASA has created a collaboration with companies and citizens and networks of Open Innovation, which connect millions of online freelance professionals (Rader 2018, p.4). Out of these networks, NASA has received solutions from individuals and teams created in the framework of challenges that NASA has launched, helping the agency save cost.

According to data shared during the US Government Open Innovation Summit, more than 100 federal agencies have participated in the US government's Open Innovation efforts (US Government Open Innovation Summit, p.6). The following can be found among the prize types in question: analytics, entrepreneurship, ideas, design, scientific, software, technology (US Government Open Innovation Summit 2019, p.8).

Innovation policy proposals by Business Roundtable and other experts

The National Innovation System study in the US especially notes that the US lacks an innovation policy. At the same time, this means that the US still has many capacities that are not exhausted, on which a new path can be built.

Aspen Cybersecurity Group considers that the US government should lead the way by enabling focus, funding, and willingness to take risks and reexamining government policies in defense, immigration, education, tax, and trade. What is required for America right now, in their view, is a whole-of-government, if not a whole-of-society effort, something that has also been mentioned by other experts writing or speaking on this issue (Aspen Cybersecurity Group 2019, p.18). Furthermore, the government should build a national consensus regarding research priorities and organize specific grand challenges in research that would provide an opportunity to partner with the private sector to support specific work (Aspen Cybersecurity Group 2019, p.18).

Economists Gruber and Johnson make an exciting proposal, namely the introduction of an innovation dividend to be paid directly to the taxpayers as a direct return on public investment on R\&D. They further elaborate on how this dividend will be financed, and then, based on the model of one of the most successful redistribution programs in the US, the Alaska Permanent Fund, they also make suggestions on how it can be distributed (Gruber \& Johnson 2019, p.191-195).

Business Roundtable (BRT), the association of chief executive officers of major US companies, which in 2019 changed its statement on the purpose of a corporation by moving away from shareholder primacy to include a commitment to all stakeholders and obligations to society (Benoit, 2019), has proposed an American Innovation Agenda for 2020. Among the most interesting vital facts that BRT sets as a basis for their thought process is that $6 \%$ of all existing US federal regulations have never been updated. (Business Roundtable 2019, p.1-2) The principles which they consider as necessary for American Innovation and based on which they develop their policy recommendations, in a summarized form are (Business Roundtable 2019, p.7-33):

1. Investing in people: by building a pipeline of students with globally competitive $21^{\text {st }}$-century skills;

2. Making strategic, long-term investments in science and technology: by developing and implementing whole-of-government strategic planning for $\mathrm{R} \& \mathrm{D}$ and by increasing funding for $\mathrm{R} \& \mathrm{D}$ leading to commercialization;

3. Removing roadblocks to innovation;

4. Positioning America to compete and thrive worldwide: among others by combatting intellectual property theft; by countering technology restrictions through partnering with like-minded countries and negotiating commitments on forced technology transfers; by leading in the development and enforcement of international commitments, standards, norms, and best practices;

5. Pursuing inclusive innovation at a time when it is expected that by 2030 , between 13 million and 54 million US workers may need to switch into an entirely new occupation due to technological change.

Gruber \& Johnson are firmly in favor of more public investments in R\&D based on several arguments they have collected through research. In previous years, the US has invested $2 \%$ of its GDP in science. Being a US\$20 trillion economy, that would mean that today the public investment in science should be nearly US $\$ 400$ billion, which it is not (Gruber \& Johnson 2019, p.110). 


\section{The US Military and its prominent role in enabling innovation in the USA}

Silicon Valley's roots can be found in the US military with Fairchild Semiconductor, considered as its pioneer startup that made its start through military contracts (Dembosky, 2013). Then, Lockheed set up its business in Sunnyvale and got a contract to build all the submarine missiles for the US, which enabled it to proliferate within four years from zero to 25000 employees (Dembosky, 2013). The importance of the US Department of Defense when it comes to innovation and technology has been crucial. The US Department of Defense and its willingness to fund innovation has been the starting base for all modern high tech (Dembosky, 2013). As research agencies in the military are also seeking broader input for their R\&D endeavors, the military has been organizing open innovation contests that attract a broad audience interested in technology, especially military technology (IdeaConnection, 2013).

Also, the case of DARPA - the Defense Advanced Research Projects Agency is an organization using open innovation methods to reach its goals better instead of using traditional technology-development approaches. Until 2018, DARPA had organized 20 open innovation challenges amounting to millions of dollars, run through the governmental portal challenge.gov. DARPA considers that organizing such challenges helps them to (Amato 2018, p.60):

- Solve a problem for which solutions through traditional means are not possible;

- Foster innovation by way of nontraditional or unexpected situations;

- Develop a new R\&D community that attracts diverse talent and widens performer base;

- Encourage STEM among students;

- Attract the kind of public attention that can assist recruiting, inform Congress, and generally enhance the DARPA "brand."

DARPA also implements other open innovation methods to seeks ideas (DARPA 2016, p.11-12):

- It organizes one-to-one meetings with researchers;

- It publishes Broad Agency Announcements;

- It sends requests for information asking experts for information on their current work in fields of interest for DARPA;

- It enables competitions to search for innovative ideas from a wide range of performers (open to all groups of citizens, a low-cost method to complement R\&D funding).

DARPA stands as the most prominent example of an organization fully dedicated to enabling innovations of a vital scale, to be in first place implemented in the US army, but which in many cases have found their way to the civil sector and have become a basis for the modern economy worldwide, such as the internet, cloud computing, GPS, speech recognition, satellite imagery (Greenwald, 2013).

There have been efforts in the past to implement DARPA's success model in the private sector too, and studies and articles have also been produced to identify what are the secrets of DARPA's innovation machine (Greenwald, 2013) or how DARPA attacks problems with its "Special Forces" Innovation method (Dugan \& Gabriel, 2013).

One of the main reasons why DARPA is considered to have been successful is its firm commitment to push the frontiers of basic science, is a dedicated work conducted in what has been described as Pasteur's Quadrant, following the quest to address pressing societal needs as once the scientist Louis Pasteur did by working to fight diseases like tuberculosis, anthrax, and rabies, and preventing food spoilage (Dugan \& Gabriel, 2013). Another important reason is considered to be the fact that DARPA has been successful in transferring its technologies - the prototypes to the Department of Defense and/or the commercial world through its technology transition process. This successful transition has been supported by several features of the DARPA model and the overall US innovation system such as (Van Atta 2018, p.18):

- DARPA's willingness to challenge incumbent technologies;

- A community of technology advocates which DARPA has helped create and grow;

- Close ties to Department of Defense leaders;

- Connection to technically sophisticated customers. 


\section{A Cultural Perspective on Innovation in the USA}

The framework developed by Hofstede and the scores calculated facilitates understanding how the American individual and society also function in an economic and especially innovation-related framework (Hofstede Insights, USA, 2020).

(1) Power Distance and Individualism: With a score of 40 in the Power Distance dimension, Americans do not expect and accept power distance. On the other hand, they have a very high score in the Individualism dimension (91). These characteristics can be considered favorable in creating a supportive environment for the development of (open) innovation, as innovation is about cooperation and competition. Furthermore, by analyzing these insights, the high individualism score might also explain the high esteem and veneration in American society for (scientific) inventors and successful (business) people who might make it easier to argue in favor of more (public) investments to enable inventions and innovation.

(2) Masculinity: A 62 score in the Masculinity dimension, combined with the high Individualism score, is again reflected in how Americans usually behave, in sports, in school, in their professional life. They always want to win, and they act on a "can-do" mentality which is crucial to make things move and improve. These behavior traits are essential to explain how Americans experience competition and want to thrive in business and as a country in the world, thus also in the innovation race.

(3) Uncertainty Avoidance: At 46, the Uncertainty Avoidance dimension is below average, and innovation has a particular influence, as people tend to accept new ideas and products and are willing to try something different, including technologies.

(4) Long-term orientation: The low score of 26 in the Long-term orientation dimension is perhaps the most important to understand the reason behind American businesses' expected behavior that makes decisions based on short-term aims related to the profit and loss statements. The same applies to individuals. Longterm decisions (which could also include investing in innovation) are neglected in favor of short-term results. Furthermore, this is also reflected in the consideration between current consumption and future income (public) investment. Thus, as noted, due to the American people's attitude and a vast national debt, it has become increasingly difficult for federal officials to ask American voters to pay more to support expanded financial support for innovation (Atkinson 2014, p.10).

\section{Discussion}

\section{What can the EU member countries learn from each other?}

Again, by analyzing the ranks of countries in each of the 80 indicators, it is evident that only a few countries excel among the EU countries, namely Sweden, Denmark, Netherlands, Luxembourg, Germany, and a few more, including also interestingly Malta which holds the $1^{\text {st }}$ place in the indicator of Joint Venture Strategic Alliance Deals indicator and Slovenia which holds the $2^{\text {nd }}$ place in the indicator of Scientific \& technical articles/bn PPP\$ GDP.

Even though GII does not have a single indicator calculating Open Innovation, a few indicators are essential to understand what this state could be. The authors suggest that these indicators could be:

- $\quad$ ICT use

- Government's online service

- E-participation

- University/industry research collaboration,

- State of Cluster Development

- Joint Venture Strategic Alliance Deals/bn PPP\$ GDP

- Venture Capital Deals/bn PPP\$ GDP.

The first three indicators in this list show how easy it is for citizens to get involved in the innovation process, relationship with the government, and more. The other four indicators, being all elements of Open Innovation, show the state of collaboration in the economy and indicate how to present Open Innovation in a country.

Regarding ICT use and the government's online service, there is probably a lot to learn from Denmark ranked $1^{\text {st }}$ in both indicators. Regarding E-participation, Denmark and Finland are top positioned in the $1^{\text {st }}$ place, and they could be taken as great examples to follow. Also, Spain is very well positioned by being ranked ${ }^{\text {fifth }}$. Regarding 
University/industry research collaboration, none of the EU member countries holds a top position. Nevertheless, the cases of Netherlands, ranked $4^{\text {th }}$ and Finland, ranked $5^{\text {th }}$, could be excellent examples to follow.

There are three exceptional cases regarding the State of Cluster Development, namely Germany, ranked $2^{\text {nd }}$, Italy, ranked $4^{\text {th }}$, and the Netherlands, ranked ${ }^{\text {fifth }}$. Regarding Joint Venture Strategic Alliance Deals, Malta ranked ${ }^{\text {st }}$, and Sweden, ranked $5^{\text {th }}$, could be considered the most important examples to follow. Regarding Venture Capital Deals, the EU member countries, in general, seem to be not well positioned. Only France holds an excellent placement and is ranked ${ }^{\text {fifth }}$.

\section{What can the EC learn from the USA in the field of innovation?}

The learnings from the situation the US finds itself in about innovation in 2020 can be summarized in one sentence: Innovation policy is essential, and state intervention is necessary, especially in the framework of a harsh competition at the global level. Seen from another perspective, external competition is essential, and the USA must focus permanently on innovation and not only once in many years. The external competition, just like in the case of companies, should be studied carefully so that measures can be taken on time, and the "Hertz Syndrome," which has been referred to be present in the US, should be possibly avoided as it makes policymakers inattentive to what might be necessary.

About the regulatory environment and taxes, it seems that necessary learning that can be useful for the EU is that $R \& D$ tax credit should be competitive as it provides incentives for the companies to invest in R\&D. The US right now is $26^{\text {th }}$ in the OECD ranking, and there is certainly room for improvement.

Education is critical as it creates the right mix of talents in a society that will be the one to carry on the innovation efforts. Thus, concerning the PISA study 2018, a focus should be given to enhancing mathematics and science skills. Only $4 \mathrm{EU}$ countries are placed in the top 10 list, starting only with the $5^{\text {th }}$ rank.

The US is the fatherland of Open Innovation, and both the private and the government sector show that this method is used widely to make sure that the best ideas find their way to the decision-makers to enable innovation. The example that comes from the Challenge.gov platform of the US government, in particular, is something worth being implemented not only by the EU member countries but by the EU institutions as well. The NASA example shows significant cost savings in the size of $40 \%$ per project in the case of having Open Innovation challenges that invite companies, researchers, freelance professionals to participate in solving government problems, societal problems, and/or advances science. The case of NASA is also essential about getting to know the power of freelancers organized in many Open Innovation networks online. Again, following NASA's example, creating a Center of Excellence for Collaborative Innovation could be an excellent suggestion to introduce to the EU.

Finally, the NASA initiative to open patents to inventors, for free, at least for the first three years of a company's product development, is an excellent example of the value to bring to the EU.

The 2019 benchmark study of the Task Force for American Innovation (TFAI) showed that China is first in many fields, and the situation in the AI-field was remarkably suggested to be a kind of "Sputnik moment" which will cause the US to make a shift in its policies about innovation but also to the relationship with China. Europe, in the meantime, as referred to in this TFAI report, is the world number one about scientific publications in the AI field, and different EU countries are mentioned to hold high ranks in some other indicators such as R\&D expenditures to total GDP, patent intensity, measuring the number of triadic patents for every million dollars. Thus, the situation is not so bright also for the EU member countries and Europe altogether. The critical debate conducted publicly in the media and research from different research centers and books has increased attention toward China's relationship and its deficiencies. Some critical questions that should also be asked in the EU member countries and the EU institutions as well are:

- Are companies from EU countries being demanded to undertake tech-transfers?

- Are EU countries confronted with corporate espionage and intellectual property theft of the kind of those addressed by the FBI and the Attorney General in the US?

- Are there EU countries that are collaborating with the FBI to collect and provide evidence?

- What kinds of geostrategic threats do the Belt and Road megaproject bring for the EU?

Silicon Valley's connection to the US military in its initial phase is an inspiring example of what could also be done in the EU with the perspective of creating this kind of model to deliver technological solutions for the common defense of the EU area. As European countries have not agreed to create such an army, at least something could be done to protect the member countries' cyberspace, financed with EU taxpayers' money. Cyberspace is now of vital interest for the people and the economy and is permanently vulnerable to sophisticated attacks that 
advance along with technology advancement. This would bring about projects to solve concrete societal problems of interest for the whole area and, on the other hand, it would be a catalyst to new technological advancements reached in a collaborative - Open Innovation kind of way among the member countries.

The potential of one European "Silicon Valley" or even several such areas in different EU countries that would focus on specific societal issues and be supported with EU money could act as a catalyst for more innovation in the EU. These centers might already exist, but they would need to be promoted and supported to raise awareness among European tech and science talents to not steadily look beyond Europe's borders to find a Silicon Valley and create more attraction for talents from other areas of the world.

Another example that is worth replicating in the EU area is that of DARPA. In the past two years, there have already been efforts to move in this direction. The President of France Macron proposed the development of a European DARPA as part of the EU institutions. However, back then, the work for the establishment of the European Innovation Council had already started, and according to the commissioner for research and innovation Moedas, the DARPA model is too top-down, while to have a European added value, the European structure that has to be developed should be more open, more bottom-up. The organization, which at the moment is backed by foundations, philanthropists, and donors but is aiming to get funding from national governments and the EC (Mawad, 2020), is going to lobby to get the support of all EU countries, but it seems that this task will not be easy as EIC pilot has proved to be successful. From a critical perspective, a comparison between the EIC and JEDI would make it clear that most EIC tools have a strong focus on close-to-market innovation (Vincenti, 2018).

Before starting, the founders of JEDI had studied the DARPA model and from a European perspective had identified that its success factors were (Marrécau, 2019):

(1) Funding of significant challenges by using a unique methodology and by putting businesses, startups, and research centers on an equal footing;

(2) Assessing the projects arising from these challenges based on the speed of implementation, the odds they may fall soon, opportunities for crossing frontiers.

Following the DARPA model, they have decided to be a small lean structure, initially with only ten project managers who will manage one or more projects with two years. As in the case of DARPA, the goal will be for JEDI to be perceived as a career booster, to attract the best talents. For 2018 the provisional budget was estimated at $€ 235$ million, with $€ 228$ million for funding and $€ 7$ million for operating costs, but the aim is to go up to $€ 1$ billion a year which would then be closer to what DARPA has at disposal every year (Vincenti, 2018).

Europe's way to address challenges so far has been to pump money into research and startups through various EClinked structures and uncoordinated initiatives by member countries (Mawad, 2020). However, this has not been sufficient. According to Loesekrug-Pietri, Europeans have never been in such a wrong position on the technology front. Cooperation is essential in a region often criticized for lacking coordination and having member countries going their separate ways (Mawad, 2020).

The relatively low score in the Power Distance dimension (40), combined with one of the highest scores in the individualism dimension (91), shed light on the US's kind of innovation environment. On the other hand, the most problematic cultural feature, which is worth referring to as learning, is the long-term orientation which in the case of innovation is directly related to whether R\&D investments are going to occur. Compared to its main competitor China with a score of 72 in this dimension, individuals in the US strive for quick results, while shareholders and the whole stock market system base their decisions basically on the profit and loss results published every quarter. It would be necessary for Europe to set a focus on educating business people and, in general, on changing the attitude and evaluation of businesses in the market based on short-term results. This is certainly a topic for a more thorough discussion.

The European Commission already addresses the challenges the EU is confronted with, and this section was dedicated to sharing some of the initiatives of interest, especially about (open) innovation. A mission-oriented approach, over $€ 80$ billion planned to be invested in Horizon Europe, over $€ 7$ billion in the Europe Defence Fund, other several billion under the ERDF structure and others, and a continuation of the successful EIC pilot are some of the highlights regarding EC commitment toward innovation in the EU. European Commission has furthermore set Open Innovation to be a guiding policy, together with Open Science and Open to the World. Still, EC could introduce more Open Innovation models in its day-to-day activities and promote them among the EU countries.

\section{Conclusion}

Paper addressed the emergency, the context, and the relevance of this research when the EU is ready to act and give more support for innovation, but still, need to get to know more from the best practices worldwide. The 
challenges are significant, with China rising and standing not only as a strategic competitor from an economic point of view but also as a potential challenge in the diplomatic area. In recognizing this challenge, the EU stands behind the USA but is moving in a similar direction. The decision to have a case study research paper was deemed appropriate as it matches the insights and knowledge that this paper aimed at putting across.

Moreover, the literature review dealt with the influence of culture and military on innovation. Several scholars have shown that cultural factors such as trust, group orientation, risk-taking, attitudes toward science and technology, collaborative culture, time horizon, and willingness to invest have on innovation. That section focused on a specific framework developed to describe the effects of national culture on individuals' behavior, Gert Hofstede's framework on the Cultural Dimensions. Another topic of interest was the effect of the military and defense funding and technologies on innovation systems, which has not been researched thoroughly, while the existing empirical research has used a case study approach. Both the cultural and military frameworks were part of the next section where the EU's case and the USA's case study were built. A few suggestions were made about the framework, and in the concluding chapter, suggestions about what kind of further research can be made on both these topics and what kind of policy proposals the EC can implement were presented.

Open Innovation 2.0 paradigm is a further important input when it comes to dealing with Open Innovation in Europe as it had its start precisely in the efforts undertaken by European experts to tackle this topic more concretely by addressing how corporates are moving towards addressing not only their short-term interests but societal needs too. Further important input from that section is that Open Innovation has its limits and failures that have to be considered too optimistic about its effects. Open innovation works if the innovation generation, innovation dissemination, and at the same time also innovation absorption takes place.

The empirical section provided an understanding of the EU situation about innovation. One of the factors is China, with which the EC has been trying to negotiate and sign a Comprehensive Investment Agreement since 2014. In 2019 China was recognized by the EC as a strategic competitor.

The authors also focused on how the EC addresses the existing challenges the EU faces in the field of innovation. Some of the initiatives taking place, especially about (open) innovation were shared. A mission-oriented approach that is expected to be implemented in over half of the Horizon Europe program, over $€ 80$ billion committed to being invested in Horizon Europe, which is the most extensive research and innovation program ever, over $€ 7$ billion in the Europe Defence Fund, several other billions of euros under the ERDF structure, and a continuation of the successful EIC pilot project are some of the highlights regarding the EC commitment toward innovation in the EU. EC has furthermore set Open Innovation to be a guiding policy, together with Open Science and Open to the World. Still, EC could do more by introducing more Open Innovation models in its day-to-day activities.

The internal developments in the USA related to innovation show that the country is facing several challenges, including the lack of a sophisticated innovation policy, weaknesses in the human capital system, including poor performance in PISA and TIMMS, the presence of a so-called "Hertz Syndrome" that makes Americans feel that they are first and do not need to try harder. Open innovation is a widely used method in American companies and the US government agencies, and much can be learned from the USA in this direction. China's relationship has escalated due to misdoings, including economic espionage, which is being investigated by the FBI and the Attorney General's office. The establishment of an Allied Industrial Free Trade Area and the extension of G-7 to a new D10, a 10-nation democratic coalition that can collaboratively fund and create alternatives to the Chinese $5 \mathrm{G}$ technology, were suggested.

The most important and optimistic sign came with the creation of the bi-partisan initiative to pass the Endless Frontier Act, which over five years will provide US $\$ 100$ billion for the National Science Foundation and US\$10 billion for the local technology hubs. At the same time, an exciting proposal has been made by two economists to establish an innovation dividend to be paid directly to the American taxpayers.

With its contribution to the creation and rise of Silicon Valley, the US military, its Open Innovation methods of finding solutions, and the excellent case of DARPA as a funding organization of essential inventions over the years, it is an excellent example.

To conclude, a cultural perspective on innovation in the USA showed that the dominant factors are a relatively low power distance that, combined with high individualism, creates a supportive environment for innovation development. On the other hand, the short-term orientation characterizing American people, including business people, leads to focusing on short-term results, thus neglecting long-term decisions such as those related to R\&D and innovation investment. 
What is essential is that the EU countries and the EC have a lot to learn from each other and the USA as that also brings other perspectives on how innovation can be done better.

The policy recommendations for the EU, based on this research, are the following:

- The innovation linkages, the university/industry research collaboration, and the presence of research talent in business enterprise show that the private sector is intensely attentive and interested in investing in innovation and, more specifically, in open innovation, which is still a new field with the potential to unfold.

- Measures such as those to enable a top-level civilian career for the retired high-rank officers as well as the purpose of the entire training system of the military aiming at creating the national serviceman as a thinking soldier further emphasize the fact that the country is a particular case worth being also considered for the case of the EU.

- From a policy point of view, the interventions of the EC could be multidimensional, just like their role is in reality. These interventions could be summarized in two pillars, the pillar dealing with the external representation and relationships of the EU with the rest of the world and the pillar dealing with the internal issues and internal market. Related to the pillar suggested to deal with the external representation and relationships of the EU, the interventions and actions, among others, could be:

- Participating in an Alliance of Democracies looking for alternatives to 5G;

- Co-establishing together with the USA of an international effort to counter China's standing about the forced tech transfer and joint ventures;

- Enabling scholarships for European tech and science talents to gain knowledge and experience in other developed markets with highly innovative activities (USA, Asia) and bring that knowledge and experience to Europe;

Related to the pillar dealing with the internal issues and market, the interventions and actions, among others, could be:

- Supporting the efforts being undertaken by the European companies Ericsson and Nokia to produce an alternative to $5 \mathrm{G}$;

- Organizing regularly European Innovation Challenges and having an Open Innovation portal such as challenge.gov in the USA;

- Considering the creation of a European DARPA or providing support for the JEDI initiative, which is already acting in this regard, and intervene in such a way that EIC and JEDI are possibly not competitors to each other but act in a complementary way;

- Requesting and promoting more the voice of business, academia, and civil society in terms of what is necessary to make Open Innovation a European reality involving the whole society;

- Supporting existing initiatives, centers, and cities all over Europe where Open Innovation has already produced remarkable results and has created a reality which is similar to hubs such as Silicon Valley so that the EU has its own "Valleys" and its role models of entrepreneurship;

- Creating and promoting an adequate Open Innovation digital environment through which the EU area can become a more attractive region for tech and science talents from all over the world, to collaborate from a distance and to move to Europe and contribute onsite for the development of more innovation;

- Creating a Startup Europe brand that supports the European startups to gain more visibility and support in their ventures to scale-up;

- Supporting and promoting successful cases of Open Innovation such as Campus Party, the case of the Austrian government program on Open Innovation, which is showing results in the top ranking in European Innovation Scoreboard or Startup Europe Partnership, the initiative to celebrate the collaboration of corporates and startups as one of the ways to undertake Open Innovation;

- Organizing EU-level educational programs for professionals and workers to reskill and gain capabilities necessary for the $21^{\text {st }}$ century, which could be activated online through digital platforms of the EC that would have to be built for this purpose in possibly an open process and in collaboration with companies and accessible professionals; 
- Working at EU level to facilitate talent discovery at high school, in collaboration with the national governments, tech and science institutions as well as businesses, to have a pool of talents based on which further dedicated programs can be built;

- Organizing educational programs to emphasize the cultural dimensions that connect Europeans and which help EU citizens deal with issues such as shame of failure, fear from risky undertakings such as entrepreneurship, lack of sense of community, and similar;

- Considering promoting the reintroduction of compulsory military service in EU countries and suggesting having dedicated training for soldiers on the values of (open) innovation and the EU as part of it.

\section{Outlook}

Open Innovation Union has never been so important and exciting as now for the EU. The rationale for more EC support for Open Innovation is there, as a whole-of-society approach seems to be the best to address the challenges arising mainly from competition at the global level. The understanding of innovation is worthwhile to be researched further. As also supported by the case study, national culture and the military are two factors that need to be followed more closely and become subject for further, deeper comparative investigations also in the future. The Hofstede cultural dimensions seem to have a significant influence on innovation, and they can certainly be influenced through lifelong educational programs and promotional campaigns. This topic deserves thorough research.

There is certainly room for a more thorough study on what compulsory military service can bring to society in terms of innovation. The military can act as a fertile ground to identify talents in science and technology and let them try, learn, and create their startups, which can then grow further in civilian life. It can help young people understand and gain values such as trust, love, and care for others, the community, and the country.

Another research issue from this paper is the discussion about the innovation indicators, especially about the Global Innovation Index. As Open Innovation has gained relevance, it might be worth regrouping some of the indicators under the title "Open Innovation" or investigate it differently. The suggestion here is to group: ICT use, government's online service, E-participation, University/industry research collaboration, State of Cluster Development, Joint Venture Strategic Alliance Deals/bn PPP\$ GDP, and Venture Capital Deals. Moreover, the case might include compulsory military service and cultural dimensions in the index as other indicators influencing innovation on the input side.

A final issue worth following in dedicated research is that of the accessible professionals engaged in EU countries collaborating with different companies participating in Open Innovation in their day-to-day activities. The importance of Open Innovation online networks and how this can affect the job market in the EU is an exciting topic, especially when compared with the trends in the USA that were presented in the chapter dedicated to the US case study.

Contrary to what is thought, the EC is very reactive to suggestions aiming at improving the well-being of EU citizens and the stand of the EU at the global level. The way EC has reacted to suggestions related to implementing Open Innovation as a method demonstrates this. Until 2015, the EU innovation policy was based on the idea of an Innovation Union, and ever since, the basis is open science, open innovation, and open to the world. Thus, to conclude, the hope is there, at least regarding the specific topic handled in this paper, that the EU has the potential, capability, and readiness to become an Open Innovation Union.

\section{References}

Amato, I. (2018). Jump-Starting Innovation: DARPA's Grand Challenges. In: DARPA 60 years 1958-2018. Retrieved 1 August 2020, from https://www.darpa.mil/attachments/DARPA60_publication-no-ads.pdf

Aspen Cybersecurity Group (2019). An Innovation Challenge for the United States. The Aspen Institute, 2019. Retrieved 1 August 2020, from https://www.aspeninstitute.org/publications/an-innovation-challenge-for-theunited-states/

Atkinson, R. D. (2014). Understanding the US National Innovation System. The Information Technology \& Innovation Foundation, June 2014. Retrieved 15 May 2020, from http://www2.itif.org/2014-understandingus-innovation-system.pdf

Avadikyan, A., Cohendet, P., \& Dupouët, O. (2005). A Study of Military Innovation Diffusion Based on Two Case Studies. In Innovation Policy in a Knowledge-based Economy, edited by P. P. Llerena and Mireille Matt, 161189. Berlin Heidelberg: Springer. https://doi.org/10.1007/3-540-26452-3_7

Benoit, D. (2019). Move Over, Shareholders: Top CEOs Say Companies Have Obligations to Society. Wall Street 
Journal, 19 August 2019. Retrieved 10 August 2020, from https://www.wsj.com/articles/business-roundtablesteps-back-from-milton-friedman-theory-11566205200

Beugelsdijk, S., \& Welzel, C. (2018). 'Dimensions and dynamics of national culture,' Journal of Cross-Cultural Psychology, Vol. 49, No. 10, November 2018. https://doi.org/10.1177/0022022118798505

Beun, H., van Schaik, M., \& Schout, A. (2019). The innovation potential of the EU budget 2021-2027. The policy brief, Clingendael - Netherlands Institute of International Relations, January 2019. Retrieved on 10 May 2019, from https://www.clingendael.org/sites/default/files/2019-01/PB_Innovation_EU_Budget_0.pdf

Bogers et al. (2016). The open innovation research landscape: established perspectives and emerging themes across different levels of analysis, Industry, and Innovation, 24:1, 8-40. https://doi.org/10.1080/13662716.2016.1240068

Business Roundtable. (2019). Innovation Nation: An American Innovation Agenda for 2020. Business Roundtable, $\begin{array}{llllll}\text { January } & 2019 . & \text { Retrieved } & 10 & \text { May } & \text { 2020, from }\end{array}$ https://s3.amazonaws.com/brt.org/BRT_Innovation_Nation_Agenda.pdf

Chesbrough, H. (2020). Open Innovation Results. Going beyond the hype and getting down to business. Oxford University Press, 2020. Kindle Edition. https://doi.org/10.1093/oso/9780198841906.001.00001

Chesbrough, H. (2003). Open Innovation - The New Imperative for Creating and Profiting from Technology. Harvard Business School Press, 2003.

Chesbrough, H, Vanhaverbeke, W., Bakici, T., \& Lopez, H. (2011). Open Innovation and Public Policy in Europe. ESADE Business School \& the Science I Business Innovation Board AISBL.

DARPA. (2016). Innovation at DARPA. July 2016. Retrieved 30 July 2020, from https://www.darpa.mil/attachments/DARPA_Innovation_2016.pdf

Dembosky, A. (2013). Silicon Valley rooted in backing from US military. Financial Times, 9 June 2013. Retrieved 1 August 2020, from https://www.ft.com/content/8c0152d2-d0f2-11e2-be7b-00144feab7de

Dugan, R. E., \& Gabriel, K. J. (2013). "Special Forces" Innovation: How DARPA Attacks Problems. Harvard Business Review, October 2013. Retrieved 30 July 2020, from https://hbr.org/2013/10/special-forcesinnovation-how-darpa-attacks-problems

European Commission. (2016). Open Innovation, Open Science, Open to the World, 2016. https://doi.org/10.2777/061652

European Commission. (2019a). Horizon Dashboard - H2020, FP7 Project Results: Reported IPRs and Scientific Publications. Release Note of March 2019. Retrieved 23 April 2019, from http://ec.europa.eu/research/participants/data/ref/h2020/other/dashboard/190320-release-notes_en.pdf

European Commission. (2019b). Enhanced European Innovation Council (EIC) pilot. Retrieved on 30 April 2019, from https://ec.europa.eu/research/eic/index.cfm?pg=funding

European Commission. (2019c). EU Budget for 2021-2027: Commission welcomes provisional agreement on Horizon Europe, the future EU research and innovation program. Press release. Retrieved on 20 March 2019, from http://europa.eu/rapid/press-release_IP-19-1676_en.htm

European Council. (2018). Simpler use of EU funds: Council confirms deal with Parliament, 19 April 2018. Retrieved on 10 May 2019, from https://www.consilium.europa.eu/en/press/pressreleases/2018/04/19/simpler-use-of-eu-funds-council-confirms-deal-with-parliament/

European Council. (2020). Special meeting of the European Council (17, 18, 19, 20, and 21 July 2020)Conclusions. EUCO 10/20, 21 July 2020. Retrieved 15 September 2020, from https://www.consilium.europa.eu/media/45109/210720-euco-final-conclusions-en.pdf

EU Monitor. (2018). Omnibus regulation: simpler rules for the use of EU funds adopted. 16 July 2018. Retrieved $\begin{array}{lllll}\text { on } 10 & \text { May 2019, from }\end{array}$ https://www.eumonitor.eu/9353000/1/j9vvik7m1c3gyxp/vkq3elp3cgzp?ctx=vgaaaujza2vo\&v=1\&d=23-09$2018 \&$ start_tab $0=20$

Executive Agency for Small and Medium-Sized Enterprises. (2020). Deep Tech Europe: European Innovation Council Pilot Impact Report 2020, September 2020. Retrieved 1 October 2020, from https://ec.europa.eu/research/eic/pdf/ec_eic_deep-tech-report-2020.pdf

Feulner, E. (2018). America is Still the Home of Innovation. Heritage Foundation, 4 April 2018. Retrieved 20 
August 2020, from https://www.heritage.org/conservatism/commentary/america-still-the-home-innovation.

Friedrich Naumann Foundation. (2020). EU Budget 2021-2027: What is in It for Europe's Defence? 6 August 2020. Retrieved 15 September 2020, from https://fnf-europe.org/2020/08/06/eu-budget-2021-2027-whats-in-it-foreuropes-defence/

Global Innovation Index. (2018). The Global Innovation Index 2018: Energizing the World with Innovation, Cornell University, INSEAD, WIPO, Ithaca, Fontainebleau, and Geneva. Available online at https://www.globalinnovationindex.org/ gii-2018-report. ISBN 978-2-38192-000-9

Global Innovation Index. (2019). The Global Innovation Index 2019: Creating Healthy Lives, The Future of Medical Innovation, Cornell University, INSEAD, WIPO, Ithaca, Fontainebleau, and Geneva. ISBN 979-1095870-14-2.

Greenwald, T. (2013). Secrets of DARPA's Innovation Machine. Forbes, 15 February 2013. Retrieved 30 July 2020, from https://www.forbes.com/sites/tedgreenwald/2013/02/15/secrets-of-darpas-innovation-machine/

Gruber, J., \& Johnson, S. (2019). Jump-Starting America: How Breakthrough Science Can Revive Economic Growth and the American Dream. PublicAffairs, 9 April 2019. Kindle Edition.

Hofstede Insights. (2020). Country comparison, USA. Retrieved 30 July 2020, from: https://www.hofstedeinsights.com/country-comparison/the-usa/

Hofstede, G. (2011) Dimensionalizing Cultures: The Hofstede Model in Context, Online Readings in Psychology and Culture. Available online at https://scholarworks.gvsu.edu/orpc/vol2/ iss1/8/ (accessed 12 January 2020).

IdeaConnection. (2013). How the Military is Embracing Open Innovation. 29 May 2013. Retrieved 30 July 2020, from https://www.ideaconnection.com/blog/innovation/how-the-military-is-embracing-openinnovation.html

Julius Raab Stiftung. (2015). Eine Open-Innovation-Strategie für Österreich: Grundlagen, Handlungsfelder, Maßnahmen, Juni 2015. Retrieved on 15 April 2019, from: http://www.juliusraabstiftung.at/wpcontent/uploads/2017/06/Open-Innovation.pdf

Marrécau, C. (2019). JEDI - Joint European Disruptive Initiative - the European DARPA. FuturaMobility, 8 January 2019. Retrieved 20 September 2020, from https://futuramobility.org/en/jedi-joint-europeandisruptive-initiative-the-european-darpa/

Mawad, M. (2020). Meet the JEDI fighting Covid... and for Europe's tech future. Sifted, 5 June 2020. Retrieved 20 September 2020, from https://sifted.eu/articles/jedi-innovators/

Mazzucato, M. (2018), Mission-Oriented Research \& Innovation in the European Union. Directorate-General for Research and Innovation, 21.02.2018. https://doi.org/10.2777/360325

Naudé, W. (2019). The Surprising Decline of Entrepreneurship and Innovation in the West. The Conversation, 8 October 2019. Retrieved 20 August 2020, from https://theconversation.com/the-surprising-decline-ofentrepreneurship-and-innovation-in-the-west-124552

Rader, S. N. (2018). Opening Up Innovation at NASA. Retrieved 1 August 2020, from https://www.slideshare.net/crowdsourcingweek/opening-up-innovation-at-nasa-nasas-open-innovationtoolkit-and-experience?from_action=save

Schmid, J. (2017). The Diffusion of Military Technology, Defence and Peace Economics. https://doi.org/10.1080/10242694.2017.1292203

The Task Force on American Innovation. (2019). Second Place America? Increasing Challenges to US Scientific Leadership, May 2019. Retrieved 1 August 2020, from http://www.innovationtaskforce.org/wpcontent/uploads/2019/05/Benchmarks-2019-SPA-Final4.pdf

The University of South California on Case Study Research Papers. (2020). USC Libraries. Research Guides. Retrieved 1 August 2020, from https://libguides.usc.edu/writingguide/casestudy

US Government. (2019). US Government Open Innovation Summit: Transformation Through Citizen Science and Prize Competitions, 14 June 2019. Retrieved 1 August 2020, from https://digital.gov/pdf/Open-InnovationSummit-June-2019.pdf

Van Atta, R. H. (2018). DARPA - The Innovation Icon at 60. In: DARPA 60 years 1958-2018. Retrieved 1 August 2020, from https://www.darpa.mil/attachments/DARAPA60_publication-no-ads.pdf

Vincenti, D. (2018). Return of the JEDI: European disruptive technology initiative ready to launch. Euractiv, 14 
March 2018. Retrieved 20 September 2020, from https://www.euractiv.com/section/economyjobs/news/return-of-the-jedi-european-disruptive-technology-initiative-ready-to-launch/

Watney, C. (2020). America's Innovation Engine is Slowing. The Atlantic, 19 July 2020. Retrieved 20 August, from https://www.theatlantic.com/ideas/archive/2020/07/americas-innovation-engine-slowing/614320

West, J., \& Bogers, M. (2017). Open innovation: current status and research. Organization \& Management Volume 19, 2017 - Issue 1. https://doi.org/10.1080/14479338.2016.1258995

World Economic Forum and McKinsey. (2019). Innovate Europe Report 2019, p.4. Retrieved 15 April 2019, from http://www3.weforum.org/docs/WEF_Innovate_Europe_Report_2019.pdf

\section{Notes}

Note 1. The methodological approach follows the guidelines published by the University of South California on Case Study Research Papers. USC Libraries. Research Guides. https://libguides.usc.edu/writingguide/casestudy.

Note 2. The questions were drawn and adapted by the Case Study Research Paper Guide of the University of South California. USC Libraries. Research Guides. https://libguides.usc.edu/writingguide/casestudy

Note 3. This table was compiled based on the ranking of the Global Innovation Index (2019, p.xxxiv)

Note 4. PISA - Programme for International Student Assessment: measures 15-year-old pupils' reading, mathematics, and science literacy with the primary domain of study rotating between reading, mathematics, and science in each cycle.

Note 5. TIMMS - Trends in International Mathematics and Science Study: a series of international assessments of the mathematics and science knowledge worldwide.

\section{Copyrights}

Copyright for this article is retained by the author(s), with first publication rights granted to the journal.

This is an open-access article distributed under the terms and conditions of the Creative Commons Attribution license (http://creativecommons.org/licenses/by/4.0/). 